\title{
Outcomes and Associated Factors of Cataract Surgery Among Adults Attending a Tertiary Hospital in Addis Ababa, Ethiopia
}

This article was published in the following Dove Press journal: Patient Related Outcome Measures

\section{Cherinet M Markos \\ Lemlem T Tamrat Mulusew A Asferaw}

Department of Ophthalmology, St. Paul's Hospital Millennium Medical College, Addis Ababa, Ethiopia
Correspondence: Lemlem T Tamrat Saint Paul's Hospital Millennium Medical College, PO Box: I27I, Addis Ababa, Ethiopia

Tel +25I-923-34-68-00

Fax +25I-I I 2-77-47-87

Email lemlem.tamrat0@gmail.com
Background: Visual outcomes and factors associated with cataract surgery vary from country to country and within countries. This study aimed to evaluate associated factors and visual outcomes following cataract surgery among adults attending Saint Paul's Hospital Millennium Medical College (SPHMMC), Addis Ababa, Ethiopia.

Patients and Methods: We conducted a prospective, longitudinal study of consecutive adult patients scheduled for cataract surgery between May 2018 and April 2019. Preoperative, intraoperative and postoperative data were collected and analyzed using SPSS version 23.0. Descriptive statistics and binary logistic regressions were used to analyze the data. We used World Health Organization (WHO) criteria for cataract surgery outcome assessment as a reference for comparison.

Results: Three hundred fourteen eyes of 314 participants (mean age $64.16 \pm 8.83$ SD, 52\% females, $44 \%$ from rural location) were included in the study. Most, $283(90.1 \%)$ had preoperative visual acuity less than 6/60. At final follow-up visit (6 to 8 weeks), bestcorrected visual acuity (BCVA) was good $(\geq 6 / 18)$ in $215(68.5 \%)$, borderline $(<6 / 18-6 / 60)$ in $63(20.1 \%)$ and poor $(<6 / 60)$ in $36(11.5 \%)$ eyes. Age-related macular degeneration $(\mathrm{AMD})[\mathrm{OR}=4.57,95 \% \mathrm{CI}[1.12-17.24], \mathrm{p}=0.03]$ and preoperative astigmatism $[\mathrm{OR}=$ $3.22,95 \%$ CI [1.25-8.33], $\mathrm{p}=0.01]$ were significantly associated with poor postoperative visual outcome.

Conclusion: While the majority of patients had good postoperative BCVA following cataract surgery, the percentage of patients with poor visual outcomes was higher than the WHO standard. Greater attention to pre-existing co-morbidities such as retinal disease and high astigmatism could improve outcomes by optimizing patient selection and surgical approach.

Keywords: cataract surgery, Ethiopia, factors, outcome

\section{Introduction}

Unoperated cataract remains one of the most common causes of blindness responsible for around $50 \%$ of all global blindness. ${ }^{1}$ More than $90 \%$ of cataract-associated blindness is found in low and middle-income countries. ${ }^{2,3}$ Achieving effective cataract surgery skills and the implementation of surgical programs are the most critical tools toward alleviating cataract blindness. It is important to assess cataract surgery outcomes in developing countries, where postoperative visual function following cataract surgery lag behind minimum international standards. Research has demonstrated a considerable variability of post-operative visual outcomes both 
between and within countries. A number of factors may explain these differences, including surgical skill, ocular co-morbidities, patient selection, postoperative management and surgical facilities. ${ }^{3}$

The World Health Organization (WHO) recommends that poor visual acuity $(\mathrm{V} / \mathrm{A}<6 / 60)$ or borderline visual acuity (V/A <6/18-6/60) following cataract surgery should not exceed more than $5 \%$ each after best available correction. $^{3}$

Many studies reported that $30-40 \%$ of eyes undergoing cataract surgery have a postoperative BCVA less than 6/ 60 , which does not meet the individual's daily visual demand in many developing countries. ${ }^{4,5}$ Some of the reasons given for such poor visual outcomes have included pre-existing ocular co-morbidities, surgical complications, limited surgical skill, inadequate postsurgical optical correction and improper preoperative biometry measurement. ${ }^{6}$ Additional factors associated with poor visual outcomes following cataract surgery have included older age, female gender, lower education attainment, rural residence, and treatment at government hospitals or through free surgery campaigns. ${ }^{6}$

Recent large reviews from high-income countries have shown improved quality of life after cataract surgery. ${ }^{7,8}$ Despite many developments and advancements in the surgical management of cataract, there is still significant concern regarding poor visual outcomes after cataract surgery in many developing countries. The percentage of poor visual outcomes ranges from $11.4 \%$ to as high as $44.0 \%{ }^{9-16}$

Ideally, standards of care should be firmly established in order to improve cataract surgical outcomes globally. Assessment of cataract surgery outcomes and the factors associated with those outcomes is a necessary step towards improving cataract management in developing countries. The aims of this study, then, were to determine visual outcomes following manual small incision and phacoemulsification cataract surgery and to analyze factors associated with poor postoperative visual outcome at SPHMMC, a tertiary eye care and training center in Addis Ababa, Ethiopia.

\section{Patients and Methods Study Design and Setting}

We performed a prospective, longitudinal study on consecutive patients who underwent cataract surgery between May 2018 and April 2019, at SPHMMC; a tertiary eye care and training center in Addis Ababa, Ethiopia.

\section{Sample Size and Sampling Technique}

From the targeted 322 eyes, 314 eyes were accepted for the study while the remaining 8 participants were excluded due to lost on follow-up. The study was conducted among consecutive adults aged 50 years and older who were diagnosed with a visually significant cataract and scheduled for surgery.

\section{Data Collection Instrument and Procedure}

Patient data was collected by residents in the SPHMMC ophthalmology department using a standardized-structured questionnaire (Supplementary Material), which was adapted from WHO recommended cataract surgery record form with some modifications to fit into our set up. Pretest was performed before the actual data collection time to minimize bias. We used a local language translators when required. Neither the operating ophthalmologist nor the operating resident were informed about each case under investigation and the actual data was collected by the assisting resident.

A total of 8 consulting ophthalmologists with variable degree of experience and 6 ophthalmology residents were participated in this study. Written and signed informed consent was obtained from each patient before the surgery. Sociodemographic data including age, gender, address, educational status, marital status, occupation, ethnicity and smoking, and alcohol consumption were obtained prior to surgery. For all patients, we recorded snellen visual acuity, non-contact air puff and/or Goldman applanation intraocular pressure (IOP), slit lamp examination of the anterior segment and of the posterior segment using a $90 \mathrm{D}$ Volk lens after pupil dilation with tropicamide $1 \%$. Every patient was checked for common systemic diseases such as hypertension and diabetes. Ocular biometry measurement and the availability of proper intraocular lens were also determined prior to the procedure. For those with dense cataract obscuring visualization, B-scan ultrasound was used to assess the posterior segment.

Topical tetracaine followed by $5 \%$ povidone iodine drops were instilled into the eye in the operating theatre prior to surgery. Patients had either retro-bulbar anesthesia (RBA) or sub-tenon anesthesia (STA) injection of lidocaine $2 \%$ with or without adrenaline and cataract extraction and lens implant by either phacoemulsification or 
manual small incision cataract surgery (MSICS) according to the preference of the surgeon.

For all MSICS cases, the wound was located superiorly and we use crescent blade bevel up with size 2.8 to $3.2 \mathrm{~mm}$ for tunnel formation and keratome blade $3.2 \mathrm{~mm}$ size angled 45 degree to enter anterior chamber (AC) and enlarge internal edge of the wound. The average external wound size was 6-7 $\mathrm{mm}$ depending on the expected nucleus size. Sideport 45 degree was used to make paracentesis. We implanted Polymethyl methacrylate (PMMA) rigid intraocular lenses.

For all phacoemulsification procedures we used MEDISONIC, CHAXU model phacoemulsification machine and the same keratome and sideport blades were used to make stab incisions on the cornea. For these group of patients hydrophobic we inserted acrylic foldable intraocular lens (IOL) implant.

During both surgical procedures, either dispersive or cohesive ophthalmic visco-surgical devices (OVD) were used, depending on the availability at the time of surgery.

Sub-conjunctival gentamicin-dexamethasone injection was given at the end of surgery. Finally, the operated eye was covered after instilling topical Ciprofloxacin $0.3 \%$ and Dexamethasone $0.1 \%$ eye drops. All details of the procedures and intraoperative complications, if any, were documented on the data collection sheet 2-5 minutes following the procedure by the assisting resident. The frequency of use of postoperative topical Dexamethasone $0.1 \%$ and Ciprofloxacin $0.3 \%$ were determined by the attending ophthalmologist in the light of postoperative findings.

Snellen visual acuity, intraocular pressure measurement, anterior and posterior segment examinations were documented on postoperative day one, at $1-2$ weeks and at a final visit, 6-8 weeks postoperatively. At the last visit almost all participants underwent refraction (objectively by an autorefractor then subjectively by ophthalmology residents) to determine the final postoperative BCVA. The visual outcomes of patients were categorized according to WHO criteria of postoperative visual acuity outcome classification.

\section{Operational Definition}

WHO classification of visual acuity for cataract surgery outcome was used in the study. ${ }^{3}$

Good Outcome: When BCVA after cataract surgery is $6 / 18$ or better $(6 / 6-6 / 18)$

Borderline Outcome: When BCVA after cataract surgery is $<6 / 18-6 / 60$
Poor Outcome: When BCVA after cataract surgery is worse than $6 / 60(<6 / 60-$ light perception)

\section{Data Quality Assurance and Ethical Clearance}

The principal investigator and advisors did regular supervision to monitor the accuracy and completeness of data. The study was conducted in accordance with Declaration of Helsinki and approved by the ethical review board of SPHMMC. The privacy and confidentiality of all participants were secured and signed informed written consent was obtained from all study participants.

\section{Statistical Analysis}

The collected data was entered twice, carefully cleaned and checked and analyzed using SPSS version 23.0 (www. ibm.com/products/SPSS-Statistics). Descriptive statistics such as frequency, distribution and central tendency measures were used to summarize the descriptive part of the study. A sample $t$-test was used to compare means of dependent and independent variables. Cross tabulation and binary logistic regressions were applied. For variables with p-value less than $0.20 \%$, univariable logistic regression and multivariable logistic regression analyses were conducted to adjust association between independent variables and poor BCVA at last visit. P-value less than 0.05 was considered as statistically significant.

\section{Results}

Three hundred fourteen eyes of 314 patients were included with a response rate of $97.5 \%$. The study subjects have mean age of $64.16 \pm 8.83$ years (range, 50-90 years) (Table 1).

Before cataract surgery there were 283 (90.1\%) patients with visual acuity $<3 / 60$. One hundred forty three $(45.5 \%)$ of the patients had other ocular comorbidities and nearly one third (30.9\%) had systemic diseases (Table 2).

MSICS was performed in 284 (90.4\%) and intraocular lens implantation in $98.4 \%$ of eyes. Posterior capsule rupture with vitreous loss (19 eyes, 6.1\%) was the most frequently encountered complication intra-operatively (Table 3).

The mean follow-up period was 7.5 weeks (range, 6-8 weeks). There was a significant improvement in vision after surgery $(\mathrm{p}=0.01)$ in a majority of the study participants. At the final visit, a good visual outcome was 
Table I Sociodemographic Characteristics of Adults Who Received Cataract Surgery at St. Paul's Hospital Millennium Medical College, 2018-2019 ( $n=314)$

\begin{tabular}{|c|c|c|}
\hline Variables & Category & $\mathbf{N}(\%)$ \\
\hline \multirow[t]{4}{*}{ Age (Years) } & $50-59$ & $89(28.3)$ \\
\hline & $60-69$ & $120(38.2)$ \\
\hline & $70-79$ & 91 (29.0) \\
\hline & $80-90$ & $14(4.5)$ \\
\hline \multirow[t]{2}{*}{ Sex } & Male & $150(47.8)$ \\
\hline & Female & $164(52.2)$ \\
\hline \multirow[t]{2}{*}{ Address } & Urban & $176(56.1)$ \\
\hline & Rural & $138(43.9)$ \\
\hline \multirow[t]{5}{*}{ Educational Status } & Unable to read and write & I4I (44.9) \\
\hline & Able to read and write & $50(15.9)$ \\
\hline & Primary School (I-8th) & $36(11.5)$ \\
\hline & Secondary School (9-12th) & $49(15.6)$ \\
\hline & Diploma and above & $38(12.1)$ \\
\hline \multirow[t]{5}{*}{ Religion } & Orthodox Christian & $140(44.6)$ \\
\hline & Muslim & $110(35.0)$ \\
\hline & Protestant & $49(15.6)$ \\
\hline & Catholic & $8(2.5)$ \\
\hline & Others & $7(2.2)$ \\
\hline \multirow[t]{5}{*}{ Occupation } & Retired & $196(62.4)$ \\
\hline & Government employee & $67(21.3)$ \\
\hline & Farmer & $34(10.8)$ \\
\hline & Private employee & $16(5.1)$ \\
\hline & Others & I $(0.3)$ \\
\hline \multirow[t]{4}{*}{ Marital status } & Single & $55(17.5)$ \\
\hline & Married & $233(74.2)$ \\
\hline & Divorced/Separated & $15(4.8)$ \\
\hline & Widowed & II (3.50) \\
\hline
\end{tabular}

achieved in $61.1 \%$ and $68.5 \%$ of patients before and after best correction, respectively. On the other hand, at the same last visit $13.1 \%$ and $11.5 \%$ had visual acuity $<6 / 60$ before and after best correction, respectively (Table 4).

Two hundred thirty seven $(75.5 \%)$ patients experienced one or more complications in the immediate postoperative period. The complications include striate keratopathy in $153(48.7 \%)$, corneal edema in 115 (36.6\%), raised IOP in $126(42.3 \%)$ and hyphema in 19 (6.10) patients.

At the last postoperative visit, the mean IOP was $13.76 \pm$ $3.67 \mathrm{mmHg}$ (range 6-36 mmHg) and only 11 (3.5\%) patients had an IOP $\geq 22 \mathrm{mmHg}$. Some of the late postoperative complications include pseudophakic bullous keratopathy (PBK) in 15 (4.8\%), posterior capsular opacification (PCO) in $9(2.8 \%)$ and cystoid macular edema in $5(1.6 \%)$ patients.
Table 2 Preoperative Clinical Characteristics of Adults Who Received Cataract Surgery at St. Paul's Hospital Millennium Medical College, 2018-2019 ( $n=314)$

\begin{tabular}{|c|c|c|}
\hline Variables & Category & $\mathbf{N}(\%)$ \\
\hline \multirow[t]{3}{*}{ Visual acuity } & $\geq 6 / 18$ & I (0.33) \\
\hline & $<6 / 18$ and $\geq 6 / 60$ & $30(9.57)$ \\
\hline & $<6 / 60$ to $L P$ & $283(90.10)$ \\
\hline \multirow[t]{2}{*}{ Preoperative IOP $(\mathrm{mmHg})$} & 6 to 21 & $286(91.1)$ \\
\hline & $\geq 22$ & $28(8.90)$ \\
\hline \multirow[t]{2}{*}{ Eye Operated } & Right & $154(49.0)$ \\
\hline & Left & $160(51.0)$ \\
\hline \multirow[t]{2}{*}{ Surgeon } & Ophthalmologist & $257(81.80)$ \\
\hline & Resident & $57(\mid 8.20)$ \\
\hline \multirow[t]{3}{*}{ Preoperative cataract } & Mature & $273(86.90)$ \\
\hline & Immature & $30(9.60)$ \\
\hline & Hyper-mature & II (3.50) \\
\hline \multirow[t]{4}{*}{ Ocular co-morbidities } & Glaucoma & $18(5.70)$ \\
\hline & AMD & $13(4.10)$ \\
\hline & Pseudo-exfoliation & $101(32.20)$ \\
\hline & Corneal Opacity & II (3.50) \\
\hline \multirow[t]{6}{*}{ Systemic co-morbidities } & Diabetes Mellitus & $46(14.60)$ \\
\hline & Hypertension & $68(21.70)$ \\
\hline & HIVIAIDS & $3(1.00)$ \\
\hline & Cardiac Disease & $2(0.67)$ \\
\hline & Bronchial Asthma & $2(0.67)$ \\
\hline & Others & $2(0.67)$ \\
\hline
\end{tabular}

Abbreviations: AMD, age-related macular degeneration; HIV/AIDS, human immunodeficiency virus/acquired immunodeficiency syndrome; LP, light perception; IOP, intraocular pressure.

A secondary surgical procedure was performed for those individuals who required additional surgical intervention. Cortical wash out was done in $4(1.3 \%)$ and hyphema was surgically treated in $3(1.0 \%)$ patients. Yttrium-aluminum-garnet (YAG) capsulotomy was performed for dense PCO in $5(1.6 \%)$ of eyes.

Applying univariate logistic regression, age, pseudoexfoliation, glaucoma, preoperative IOP, AMD, presence of intraoperative complications and preoperative $\mathrm{K}$ reading/ astigmatism were significantly associated with poor postoperative BCVA. With multivariate logistic regression, $\mathrm{AMD}(\mathrm{OR}=$ $4.57,95 \% \mathrm{CI}[1.12-17.24], \mathrm{p}=0.03)$ and preoperative astigmatism $(\mathrm{OR}=3.22,95 \% \mathrm{CI}[1.25-8.33], \mathrm{p}=0.01)$ were significantly associated with poor BCVA (Table 5).

\section{Discussion}

In this study, we evaluated the overall visual outcomes and factors associated with poor post-operative BCVA 
Table 3 Intraoperative Characteristics of Adults Who Received Cataract Surgery at St. Paul's Hospital Millennium Medical College, 2018-2019 ( $n=314)$

\begin{tabular}{|c|c|c|}
\hline Variables & Category & $\mathbf{N}(\%)$ \\
\hline Anesthesia type & $\begin{array}{l}\text { Sub-Tenon's anesthesia } \\
\text { Retrobulbar anesthesia }\end{array}$ & $\begin{array}{l}172 \\
(54.60) \\
142 \\
(45.40)\end{array}$ \\
\hline $\begin{array}{l}\text { Anesthesia } \\
\text { complications }\end{array}$ & $\begin{array}{l}\text { Yes } \\
\text { No }\end{array}$ & $\begin{array}{l}4(1.30) \\
310 \\
(98.7)\end{array}$ \\
\hline Type of surgery & $\begin{array}{l}\text { MSICS } \\
\text { Phacoemulsification }\end{array}$ & $\begin{array}{l}284 \\
(90.40) \\
30(9.60)\end{array}$ \\
\hline Wound section & $\begin{array}{l}\text { Scleral Tunnel } \\
\text { Clear corneal }\end{array}$ & $\begin{array}{l}284 \\
(90.40) \\
30(9.60)\end{array}$ \\
\hline Capsulotomy & $\begin{array}{l}\text { Can opener } \\
\text { CCC }\end{array}$ & $\begin{array}{l}284 \\
(90.40) \\
30(9.60)\end{array}$ \\
\hline Place of intraocular lens & $\begin{array}{l}\text { Posterior chamber (PC) } \\
\text { Anterior chamber (AC) } \\
\text { Surgical aphakia }\end{array}$ & $\begin{array}{l}304 \\
(96.80) \\
5(1.60) \\
5(1.60)\end{array}$ \\
\hline $\begin{array}{l}\text { Intraocular lens } \\
\text { material }\end{array}$ & $\begin{array}{l}\text { PMMA } \\
\text { Acrylic }\end{array}$ & $\begin{array}{l}280 \\
(89.20) \\
29(9.20)\end{array}$ \\
\hline $\begin{array}{l}\text { Intraoperative } \\
\text { complications }\end{array}$ & $\begin{array}{l}\text { PC rupture with vitreous } \\
\text { loss } \\
\text { Premature AC entry } \\
\text { Retained cortical matter } \\
\text { Iridodialysis } \\
\text { Zonular dialysis } \\
\text { Wound leak } \\
\text { Others }\end{array}$ & $\begin{array}{l}19(6.10) \\
6(1.90) \\
4(1.34) \\
5(1.60) \\
3(1.00) \\
17(5.40) \\
1(0.33)\end{array}$ \\
\hline
\end{tabular}

Abbreviations: AC, anterior chamber; CCC, continuous curvilinear capsulorhexis; MSICS, manual small incision cataract surgery; PC, posterior chamber; PMMA, poly methyl methacrylate.

following cataract surgery. Though there was significant improvement in visual acuity, our results suggest that at 6-8 weeks following surgery, a majority of eyes achieved a BCVA below the minimum WHO standard for cataract surgery outcomes ( $\geq 6 / 18$ in $90 \%$ with $<5 \%$ having vision less than $6 / 60){ }^{3}$

The number of patients with good visual outcome in our study was also lower than that found in a study
Table 4 Preoperative and Postoperative Vision of Adults After Cataract Surgery at St. Paul's Hospital Millennium Medical College, 2018-2019 (n=314)

\begin{tabular}{|l|l|l|l|}
\hline \multirow{2}{*}{$\begin{array}{l}\text { Time of Vision } \\
\text { Measurement }\end{array}$} & \multicolumn{3}{|l|}{ VA Category N (\%) } \\
\cline { 2 - 4 } & $\mathbf{7 6 / 1 8}$ & $\mathbf{6 / 1 8 - 6 / 6 0}$ & $<6 / 60$ \\
\hline $\begin{array}{l}\text { Pre-operative time } \\
\text { (Before surgery) }\end{array}$ & $\mathrm{I}(0.3)$ & $30(9.6)$ & $283(90.1)$ \\
$\begin{array}{l}\text { Day I after surgery } \\
\text { Week I-2 after surgery }\end{array}$ & $85(27.1)$ & $97(30.9)$ & $132(42.0)$ \\
$\begin{array}{l}\text { Week 6-8 after surgery } \\
\text { (Before correction) }\end{array}$ & $192(61.1)$ & $115(36.6)$ & $62(19.7)$ \\
$\begin{array}{l}\text { Week 6-8 after surgery } \\
\text { (After correction) (BCVA) }\end{array}$ & $215(68.5)$ & $63(20.1)$ & $4 \mathrm{I}(13.1)$ \\
\hline
\end{tabular}

Abbreviations: BCVA, best-corrected visual acuity; VA, visual acuity.

performed in Nigerian; where good BCVA was achieved in $78.8 \%$ of cases. ${ }^{17}$ A Kenyan study similarly reported superior outcomes (uncorrected VA of 6/18 or better in $81.8 \%$ with only $2.4 \%$ poor outcomes). ${ }^{18}$

However, our findings are comparable with a study conducted in Jimma (south west Ethiopia) where good visual outcomes were achieved in $70.4 \%$ of cases. ${ }^{19}$ Comparable results were also seen across the spectrum of visual outcomes in a report from Trinidad and Tobago, where good, borderline and poor visual outcomes were $67.0 \%, 21.0 \%$ and $12 \%$, respectively. ${ }^{20}$ Poor visual outcomes following extracapsular cataract extraction (ECCE) with IOL have been reported in $9.7-15.5 \%$ of operated eyes in multiple hospital-based reports from Nigeria. ${ }^{21-23}$ Another study from Gondar (northwest Ethiopia) showed good, borderline and poor visual outcomes in $26.6 \%, 28.9 \%$ and $44.5 \%$ of operated eyes, respectively. ${ }^{24}$ That we saw relatively better outcomes in our study might be due to the fact that the majority of surgeries were performed by senior ophthalmologists and the final vision assessment being at 6-8 weeks (versus 1-4 weeks for two-thirds of patients in the Gondar study). The outcomes in our study were generally better than those from a study in India, where fair outcomes were achieved in only $50 \%$ of cases $^{25}$ and also compared to a study from Nepal, where good, borderline and poor visual outcomes were found in $41.3 \%, 45 \%$, and $13.7 \%$, respectively. ${ }^{26} \mathrm{An}$ additional study from Malawi demonstrated poor outcomes in $19.5 \%$ of cases, a number much higher that found in our study. ${ }^{27}$

During the surgical procedure, one or more complications were encountered in $29(9.20 \%)$ eyes and, posterior capsule 
Table 5 Factors Associated with Poor Visual Outcome Among Adults After Cataract Surgery at St. Paul's Hospital Millennium Medical College, 2018-2019 (n=314)

\begin{tabular}{|c|c|c|c|c|c|c|}
\hline \multirow[t]{2}{*}{ Variables } & \multicolumn{2}{|c|}{ BCVA } & \multirow{2}{*}{$\begin{array}{l}\text { COR }(95 \% \mathrm{Cl}) \\
\text { Univariate Logistic } \\
\text { Regression }\end{array}$} & \multirow[t]{2}{*}{ P-value } & \multirow{2}{*}{$\begin{array}{l}\text { AOR }(95 \% \mathrm{Cl}) \\
\begin{array}{l}\text { Multivariate Logistic } \\
\text { Regression }\end{array}\end{array}$} & \multirow[t]{2}{*}{ P-value } \\
\hline & Poor & $\begin{array}{l}\text { Good to } \\
\text { Borderline }\end{array}$ & & & & \\
\hline \multicolumn{7}{|l|}{ Age } \\
\hline $50-59$ & 6 & 83 & 1.00 & & & \\
\hline $60-69$ & 14 & 106 & $0.18(0.04,0.75)$ & 0.019 & $0.83(0.28,2.46)$ & 0.63 \\
\hline $70-79$ & 12 & 79 & $0.33(0.09,1.19)$ & 0.091 & $0.65(0.22,1.93)$ & 0.55 \\
\hline $80-90$ & 4 & 10 & $0.38(0.10,1.42)$ & 0.470 & $0.34(0.06, I .7 I)$ & 0.29 \\
\hline \multicolumn{7}{|l|}{ Sex } \\
\hline Male & 15 & 135 & 1.00 & & & \\
\hline Female & 21 & 143 & $0.75(0.37,1.53)$ & 0.43 & & \\
\hline \multicolumn{7}{|l|}{ Address } \\
\hline Urban & 17 & 159 & 1.00 & & & \\
\hline Rural & 19 & 119 & $0.67(0.33,1.35)$ & 0.25 & & \\
\hline \multicolumn{7}{|c|}{ Preoperative IOP $(\mathrm{mmHg})$} \\
\hline $6-21$ & 29 & 257 & 1.00 & & & \\
\hline$\geq 22$ & 7 & 21 & $2.95(1.15,7.54)$ & 0.02 & I.7I $(0.53,5.49)$ & 0.36 \\
\hline \multicolumn{7}{|l|}{ Glaucoma } \\
\hline Yes & 4 & 14 & $2.35(0.73,7.59)$ & 0.15 & $2.12(0.49,9.09)$ & 0.31 \\
\hline No & 32 & 264 & 1.00 & & & \\
\hline \multicolumn{7}{|l|}{ AMD } \\
\hline Yes & 5 & 8 & $5.44(1.67,17.67)$ & 0.005 & $4.57(1.12,17.24)$ & $0.03 *$ \\
\hline No & 31 & 270 & 1.00 & & & \\
\hline \multicolumn{7}{|c|}{ Psudoexfoliation } \\
\hline Yes & 17 & 84 & $2.06(1.02,4.17)$ & 0.04 & I.8I $(0.80,4.00)$ & 0.15 \\
\hline No & 19 & 194 & 1.00 & & & \\
\hline \multicolumn{7}{|l|}{ Dry eye } \\
\hline Yes & 8 & 51 & $1.27(0.54,2.95)$ & 0.57 & & \\
\hline No & 28 & 227 & 1.00 & & & \\
\hline \multicolumn{7}{|c|}{ Systemic disease } \\
\hline Yes & 10 & 87 & $0.84(0.39,1.82)$ & 0.66 & & \\
\hline No & 26 & 191 & & & & \\
\hline \multicolumn{7}{|l|}{ Surgeon } \\
\hline Resident & 4 & 53 & I.88 $(0.64,5.55)$ & 0.25 & & \\
\hline & 32 & 225 & 1.00 & & & \\
\hline Ophthalmo & & & & & & \\
\hline \multicolumn{7}{|c|}{ Anesthesia } \\
\hline RBA & 14 & 128 & 1.00 & & & \\
\hline STA & 22 & 150 & I.35 $(0.66,2.77)$ & 0.41 & & \\
\hline
\end{tabular}


Table 5 (Continued).

\begin{tabular}{|c|c|c|c|c|c|c|}
\hline \multirow[t]{2}{*}{ Variables } & \multicolumn{2}{|c|}{ BCVA } & \multirow{2}{*}{$\begin{array}{l}\text { COR }(95 \% \mathrm{CI}) \\
\text { Univariate Logistic } \\
\text { Regression }\end{array}$} & \multirow[t]{2}{*}{ P-value } & \multirow{2}{*}{$\begin{array}{l}\text { AOR }(95 \% \mathrm{Cl}) \\
\text { Multivariate Logistic } \\
\text { Regression }\end{array}$} & \multirow[t]{2}{*}{ P-value } \\
\hline & Poor & $\begin{array}{l}\text { Good to } \\
\text { Borderline }\end{array}$ & & & & \\
\hline \multicolumn{7}{|l|}{ Intraoperative } \\
\hline Yes & 7 & 22 & $2.80(1.10,7.14)$ & 0.03 & $2.17(0.73,6.25)$ & 0.16 \\
\hline \multicolumn{7}{|l|}{ Complications } \\
\hline No & 29 & 256 & 1.00 & & & \\
\hline \multicolumn{7}{|c|}{ Preoperative K Reading/Astigmatism } \\
\hline-0.75 to -2 & 26 & 247 & 1.00 & & & \\
\hline-2.25 to -7.38 & 9 & 25 & $3.44(1.44,8.33)$ & 0.005 & $3.22(1.25,8.33)$ & $0.01 *$ \\
\hline \multicolumn{7}{|c|}{ Postoperative Astigmatism } \\
\hline-0.75 to -2 & 6 & 184 & 1.00 & & & \\
\hline-2.25 to -6 & 2 & 44 & $1.40(0.27,7.14)$ & 0.69 & & \\
\hline
\end{tabular}

Note: *Statistically significant (Multivariate regression).

Abbreviations: AOR, adjusted odds ratio; AMD, age-related macular degeneration; BCVA, best-corrected visual acuity; COR, crude odds ratio; IOP, intraocular pressure; $\mathrm{K}$, keratometer; RBA, retro-bulbar anesthesia; STA, sub-tenon anesthesia.

rupture with vitreous loss occurred in $19(6.10 \%)$ cases. This was the most common complication followed by premature entry into the anterior chamber in $6(1.90 \%)$ eyes and Iridodialysis in $5(1.60 \%)$ eyes. One possible reason for a relatively high complication rate in our series is the role of senior residents in performing cataract surgery at our center and the overall nationwide questionable quality of ophthalmologist training. This finding is comparable with the study done in India, where the rate of intraoperative complications were $22(8.8 \%)$ cases. $^{28}$ This also falls in line with a study done in western India in 2003, where intraoperative complications from MSICS were seen in $8.1 \%$ of cases and moderate to severe complications like posterior capsular rent and vitreous loss were seen in $5.02 \%$ of surgeries. ${ }^{29}$ Nearly similar rate of complication was reported from Jimma, Ethiopia, where 18 of 200 $(9.0 \%)$ participants had intraoperative complications. ${ }^{19}$

A low intraoperative complication rate of $1.9 \%$ following high volume cataract surgery was reported from Aravind, India in 2003. ${ }^{30}$ A similar study from Kenya reported that only 6 of $325(1.6 \%)$ surgeries experienced intraoperative complication. ${ }^{18}$

There are multiple factors associated with poor surgical outcome following cataract surgery which differ from country to country and even within the same country in different setups. Univariate logistic regression for factors associated with poor visual outcome revealed that age, preoperative ocular co-morbidities (preoperative elevated IOP, glaucoma, AMD, pseudoexfoliation), intraoperative complications and preoperative astigmatism were significantly associated with poor postoperative BCVA. Multivariate logistic regression indicated that AMD and preoperative astigmatism were significantly associated with poor visual outcome after cataract surgery. This finding is similar to the results of a study from Malaysia, in which ocular co-morbidities were significantly associated with no improvement in visual acuity following cataract surgery. ${ }^{31}$ Similar results have been reported in India ${ }^{6}$ and Trinidad and Tobago. ${ }^{20}$ The significant association of poor visual outcome with increasing age in our study has also been found in other earlier studies. ${ }^{17,32,33}$

\section{Conclusion}

In our study visual outcome following cataract operation was below the standard set by WHO. Age-related macular degeneration and preoperative astigmatism were significantly associated with poor visual outcome. Greater attention to pre-existing co-morbidities such as retinal disease and high astigmatism could improve outcomes by optimizing patient selection and surgical approach.

\section{Abbreviations}

AC, Anterior chamber; AOR, Adjusted odds ratio; AMD, Age-related macular degeneration; BCVA, Best-corrected 
visual acuity; CCC, continuous curvilinear capsulorhexis; CI, Confidence interval; COR, Crude odds ratio; ECCE, extra-capsular cataract extraction; HIV/AIDS, Human immunodeficiency virus/Acquired immunodeficiency syndrome; IOL, Intraocular lens; IOP, Intraocular Pressure; K, keratometer; LP, Light perception; MSICS, Manual small incision cataract surgery; OVD, ophthalmic visco-surgical devices PBK, Pseudophakic bullous keratopathy; PC, Posterior chamber; PCO, Posterior capsular opacity; PMMA, Polymethyl methacrylate; RBA, Retro-bulbar anesthesia; SPHMMC, St. Paul's Hospital Millennium Medical College; SPSS, Statistical package for social Sciences; STA, Sub-tenon anesthesia; UCVA, Uncorrected visual acuity; VA, Visual acuity; WHO, World Health Organization; YAG, Yttrium-aluminum-garnet.

\section{Data Sharing Statement}

The data is available from the corresponding author if requested in the form of statistical package for social sciences (SPSS).

\section{Ethics Approval and Informed Consent}

The study was approved by SPHMMC IRB directorate and informed written consent was taken from each study participant and all authors read the manuscript and agreed for publication.

\section{Acknowledgment}

We would like to thank SPHMMC for financial support and all study participants for their valuable time and commitment. The authors also would like to thank Geoffrey Woodruff and Scott Lawrence for in-depth editing of the manuscript.

\section{Author Contributions}

All authors made a significant contribution to the work reported, whether that is in the conception, study design, execution, acquisition of data, analysis and interpretation, or in all these areas; took part in drafting, revising or critically reviewing the article; gave final approval of the version to be published; have agreed on the journal to which the article has been submitted; and agree to be accountable for all aspects of the work.

\section{Funding}

The study was funded by SPHMMC and funding was used for data collection, processing, write up and statistician consultation. The funder had no role in the study.

\section{Disclosure}

The authors report no conflicts of interest for this work.

\section{References}

1. Khairallah M, Kahloun R, Bourne R, et al. Number of people blind or visually impaired by cataract worldwide and in world regions, 1990 to 2010. Invest Ophthalmol Vis Sci. 2015;56(11):6762-6769. doi:10.1167/iovs.15-17201

2. World Health Organization Global data on visual impairments; 2010. Available from: http://www.who.int/blindness/publications/global data/en/. Accessed December 5, 2020.

3. Informal Consultation on Analysis of Blindness Prevention, Outcomes W. H. O. Programme for the Prevention of Blindness Deafness. Informal consultation on analysis of blindness prevention outcomes, Geneva. World Health Organization; 1998. WHO/PBL/ 98.68 .

4. Bachani D, Gupta SK, Murthy GV, Jose R. Visual outcomes after cataract surgery and cataract surgical coverage in India. Int Ophthalmol. 1999;23(1):49-56. doi:10.1023/A:1006435312612

5. Limburg H, Foster A, Vaidyanathan K, Murthy G. Monitoring visual outcome of cataract surgery in India. Bull World Health Organ. 1999;77(6):455-460.

6. Matta S, Park J, Palamaner Subash Shantha G, Khanna RC, Rao GN. Cataract surgery visual outcomes and associated risk factors in secondary level eye care centers of L V Prasad Eye Institute, India. PLoS One. 2016;11(1):e0144853.

7. Finger RP, Kupitz DG, Fenwick E, et al. The impact of successful cataract surgery on quality of life, household income and social status in South India. PLoS One. 2012;7(8):e44268. doi:10.1371/journal. pone. 0044268

8. Lamoureux EL, Fenwick E, Pesudovs K, Tan D. The impact of cataract surgery on quality of life. Curr Opin Ophthalmol. 2011;22 (1):19-27. doi:10.1097/ICU.0b013e3283414284

9. Dandona L, Dandona R, Naduvilath TJ, et al. Population-based assessment of the outcome of cataract surgery in an urban population in southern India. Am J Ophthalmol. 1999;127:650-658. doi:10.1016/ S0002-9394(99)00044-6

10. Kandel RP, Sapkota YD, Sherchan A, Sharma MK, Aghajanian J, Bassett KL. Cataract surgical outcome and predictors of outcome in Lumbini Zone and Chitwan District of Nepal. Ophthalmic Epidemiol. 2013;17:276-281. doi:10.3109/09286586.2010.508355

11. Khanna RC, Pallerla SR, Eeda SS, et al. Population based outcomes of cataract surgery in three tribal areas of Andhra Pradesh, India: risk factors for poor outcomes. PLoS One. 2012;7(5):e35701. doi:10.1371/journal.pone.0035701

12. Lindfield R, Polack S, Wadud Z, Choudhury KA, Rashid AK, Kuper H. Causes of poor outcome after cataract surgery in Satkhira district, Bangladesh. Eye (Lond). 2008;22:1054-1056. doi:10.1038/sj. eye. 6702836

13. Murthy GV, Ellwein LB, Gupta S, Tanikachalam K, Ray M, Dada VK. A population-based eye survey of older adults in a rural district of Rajasthan: II. Outcomes of cataract surgery. Ophthalmology. 2001;108(4):686-692. doi:10.1016/S0161-6420(00) 00578-9 
14. Sapkota YD, Sunuwar M, Naito T, Akura J, Adhikari HK. The prevalence of blindness and cataract surgery in rautahat district, Nepal. Ophthalmic Epidemiol. 2010;17(2):82-89. doi:10.3109/ 09286581003624947

15. Mathenge W, Nkurikiye J, Limburg H, Kuper H. Rapid assessment of avoidable blindness in Western Rwanda: blindness in a post conflict setting. PLoS Med. 2007;4(7):e217. doi:10.1371/journal.pmed.0040217

16. Kalua K, Lindfield R, Mtupanyama M, Mtumodzi D, Msiska V. Findings from a rapid assessment of avoidable blindness (RAAB) in Southern Malawi. PLoS One. 2011;6(4):e19226. doi:10.1371/journal.pone.0019226

17. Olawoye OO, Ashaye AO, Bekibele CO, Ajayi BG. Visual outcome after cataract surgery at the university college hospital, ibadan. Ann Ib Postgrad Med. 2011;9(1):8-13.

18. Trivedy J. Outcomes of high volume cataract surgeries at a Lions Sight First Eye Hospital in Kenya. Nepal J Ophthalmol. 2011;3 (1):31-38. doi:10.3126/nepjoph.v3i1.4276

19. Addisu Z, Solomon B. Patients' preoperative expectation and outcome of cataract surgery at Jimma University Specialized Hospital Department of Ophthalmology. Ethiop J Health Sci. 2011;21 (1):47-55. doi:10.4314/ejhs.v21i1.69044

20. Sonron E-A, Tripathi V, Bridgemohan P, Sharma S. A retrospective study on the outcomes of cataract surgery in an Eastern Regional Health Authority hospital of Trinidad and Tobago. PeerJ. 2015;5(9):1-13.

21. Alhassan BM, Kyari F, Achi BI, Ozemela PC, Abiose A. Audit of outcome of an Extracapsular cataract extraction and posterior chamber intraocular lens training course. $\mathrm{Br} J$ Ophthalmol. 2000;84:848-851. doi:10.1136/bjo.84.8.848

22. Ezegwui IR, Ajewole J. Monitoring cataract surgical outcome in a Nigerian mission hospital. Int Ophthalmol. 2009;29:7-9. doi:10.1007/s10792-007-9182-2

23. Nwosu SN, Onyekwe LO. Intraocular lens implantation surgery in Onitsha, Nigeria. Niger J Ophthalmol. 2002;1:5-9.

24. Hussen MS, Gebreselassie KL, Seid MA, Belete GT. Visual outcome of cataract surgery at Gondar University Hospital Tertiary Eye Care and Training Center, North West Ethiopia. Clin Optom (Auckl). 2017;9:19-23. doi:10.2147/OPTO.S122953
25. Domple VK, Gaikwad AV, Khadilkar HA, Doibale MK, Kulkarni AP. A study on visual outcomes after cataract surgery with intraocular lens implants at the rural health-training center, Paithan, Maharashtra. Indian J Public Health. 2011;55(1):22-24. doi:10.4103/0019-557X.82539

26. Kshitiz K, Gupta VP, Dhaliwal U. Causes of sub-optimal cataract surgical outcomes in patients presenting to a teaching hospital. Nepal J Ophthalmol. 2012;4(1):73-79.

27. Chirambo MC. Country-wide monitoring of cataract surgical outcomes. Community Eye Health. 2002;15(44):58-59.

28. Patil M, Balwir D, Dua S. Study of intraoperative complications in small incision cataract surgery, its management and visual outcome. MVP J Med Sci. 2016;3(1):52-59. doi:10.18311/mvpjms/2016/v3/i1/719

29. Gogate PM, Deshpande M, Wormald RP, et al. Extracapsular cataract surgery compared with manual small incision cataract surgery in community eye care setting in western India: a randomized controlled trial. Br J Ophthalmol. 2003;87(6):667-672. doi:10.1136/bjo.87.6.667

30. Venkatesh R, Muralikrishnan R, Balent LC, Prakash SK, Prajna NV. Outcomes of high volume cataract surgeries in a developing country. $\mathrm{Br}$ J Ophthalmol. 2005;89(9):1079-1083. doi:10.1136/bjo.2004.063479

31. Thanigasalam T, Reddy SC, Zaki RA. Factors associated with complications and postoperative visual outcomes of cataract surgery; A study of 1632 cases. J Ophthalmic Vis Res. 2015;10:375-384. doi:10.4103/2008-322X.158892

32. Gogate P, Vakil V, Khandekar R, Deshpande M, Limburg H. Monitoring and modernization to improve visual outcomes of cataract surgery in a community eye care center in western India. J Cataract Refract Surg. 2011;37:328-334. doi:10.1016/j.jcrs.2010.08.034

33. Yorston D, Gichuhi S, Wood M, Foster A. Does prospective monitoring improve cataract surgery outcomes in Africa? Br J Ophthalmol. 2002;86(5):543-547. doi:10.1136/bjo.86.5.543
Patient Related Outcome Measures

\section{Publish your work in this journal}

Patient Related Outcome Measures is an international, peer-reviewed, open access journal focusing on treatment outcomes specifically relevant to patients. All aspects of patient care are addressed within the journal and practitioners from all disciplines are invited to submit their work as well as healthcare researchers and patient support groups.
Dovepress

The manuscript management system is completely online and includes a very quick and fair peer-review system. Visit http://www. dovepress.com/testimonials.php to read real quotes from published authors. 